\title{
Public Knowledge of Cardiovascular Diseases and its Risk Factors in Jeddah City, Saudi Arabia
}

\author{
Shereen Helmy Ahmed ${ }^{1}$, Yumna Abdulmalek Bokhari ${ }^{2}$, Rana Jamal Nahas ${ }^{2}$, Amjad Zaki Alharbi ${ }^{2}$, \\ Asrar Abdullah Niyazi ${ }^{2}$, Renad Abdulwahab AlGaedy ${ }^{2}$ \\ ${ }^{1}$ Faculty of Medicine, Ibn Sina National College, Jeddah, Kingdom of Saudi Arabia \\ ${ }^{2}$ Medical Students at Ibn Sina National College, Jeddah, Kingdom of Saudi Arabia \\ *Corresponding author: Renad Abdulwahab AlGaedy; Renadaalgaedy@gmail.com
}

Received 09 August 2021;

Accepted 28 August 2021;

Published 02 September 2021

\begin{abstract}
Introduction: Cardiovascular diseases (CVDs) are one of the critical yet preventable non-communicable diseases. Based on the World Health Organization (WHO) reports on non-communicable conditions in 2010, millions of people were killed by non-communicable diseases in 2008, resulting in deaths that occurred before the age of 60 (1). Our aim in this study is to provide descriptive epidemiology and to estimate the public's knowledge towards CVD types, risk factors, and warning symptoms of heart attack or stroke. Methodology: The study was approved by Ibn Sina National College of Medical Sciences research committee in November of 2019.This is a cross-sectional analytic study conducted among the Saudi community in Jeddah City, Saudi Arabia from November 2019 to April 2020. A total of 635 respondents contributed to fill the self-administered questionnaire. Statistical package for social sciences (SPSS) version 20 was used. The degree of association was tested using Chi-square. A statistically significant association was taken at $\mathrm{P}<0.05$. Results: Participants who agreed to participate consisted of 228(35.9\%) males and 407(64.1\%) females. Hypertension is the highest disease diagnosed with a total of 111(17.5\%) and highest among females with $71(64.0 \%)$. Most of the participants identified chest pain and discomfort (76.4\%) and shortness of breath $(73.7 \%)$ as symptoms of heart attack. Compared with other symptoms such as pain or discomfort in the arm or shoulder (57.3\%), weakness in the arm or leg on one side of the body (55.6\%), and weakness lightheaded and fainting (51.2\%). Conclusion: The study participants show low knowledge in CVS. There is a need to increase public awareness and to establish basic knowledge to the general and targeted individuals.
\end{abstract}

Keywords: cardiovascular disease, public knowledge, risk factors, Jeddah, Saudi Arabia

\section{Introduction}

Cardiovascular diseases (CVDs) are one of the critical yet preventable non-communicable diseases. Based on the World Health Organization (WHO) reports on non-communicable conditions in 2010, millions of people were killed by noncommunicable diseases in 2008, resulting in deaths that occurred before the age of $60^{[1]}$. Public knowledge of cardiovascular diseases and its risk factors is of great importance since it includes a diversity of disorders like coronary heart disease, cerebrovascular disease and deep vein thrombosis. CVDs are the leading cause of death globally, with more than 17.3 million deaths/per year ${ }^{[1]}$. Based on the WHO and Saudi Ministry of Health (MOH), CVDs caused $42 \%$ of deaths in 2010 in the Kingdom of Saudi Arabia (KSA). Numbers in reports also show a higher number of male patients with cardiac diseases than female patients ${ }^{[2]}$.

A cross-sectional study was conducted in 2016 in Jeddah, Saudi Arabia on the prevalence of undiagnosed cardiovascular risk factors in 507 participants aged between 20-40 years which reported that men showed a higher prevalence of high blood pressure of $10.6 \%$, while females on the other hand only showed $0.8 \%{ }^{[3]}$. Another study was done at King Abdul-Aziz University hospital regarding the physical attributes of cardiovascular risk factors among high-risk individuals that attend general practice, indicated that obesity is a crucial cause of CVDs [4]. Tobacco smoking is another leading cause of CVD, especially waterpipe smoking which has been known among people as a better alternative to cigarettes, which in fact contains an equivalent harmful chemical substances and pathologic effects ${ }^{[5]}$. Educating people about obesity and its tributaries to CVDs will make a massive difference in the number of high-risk people.

To our knowledge, data that assess public knowledge of cardiovascular diseases in Jeddah, Saudi Arabia are very limited. Our aim in this study is to provide descriptive epidemiology and to estimate the public's knowledge towards CVD types, risk factors, and warning symptoms of heart attack or stroke.

\section{Methodology}

The study was approved by Ibn Sina National College of Medical Sciences research committee in November of 2019.This is a cross- 
sectional analytic study conducted among the Saudi community in Jeddah City, Saudi Arabia from November 2019 to April 2020. A total of 635 respondents (aged 20 years and older) contributed to fill the self-administered questionnaire anonymously after taking a verbal consent either directly in public places or indirectly through an online link. The target sample size was a minimum of 377 that was calculated using Raosoft ${ }^{[6]}$.

A validated electronic questionnaire was taken from a study conducted in Nigeria that was used to know the public knowledge ${ }^{[7]}$. The survey is written in both English and Arabic languages, and the accuracy of the translation was checked. The questions included in the study are demographic characteristics of the respondents, such as gender, marital status, age, employment, educational level, and lifestyle. Other important questions that provide information about the participant's health status and knowledge. Statistical package for social sciences (SPSS) version 20 was used and descriptive analysis was conducted. The degree of association was tested using Chi-square. A statistically significant association was taken at $\mathrm{P}<0.05$.

\section{Results}

In this study we aimed to provide descriptive epidemiology and to estimate the public's knowledge towards CVD types, risk factors, and warning symptoms of heart attack or stroke.

A total of 635 questionnaires were distributed to the participants directly in shopping centers and indirectly through electronic platform during the period from November 2019 to April 2020. Data were collected anonymously via a selfadministered questionnaire. No missing value was recorded.

\section{Study population}

Table 1 illustrates the characteristics of the study participants. Participants who agreed to participate consisted of 228 (35.9\%) males and $407(64.1 \%)$. The majority of the participants had a relatively stressful lifestyle of $278(43.8 \%), 447$ (70.4\%) are not smokers, and 294 (46.3\%) don't exercise. Only 372 (58.6) reported eating fruits or vegetables sometimes, and 252 (39.7) reported eating fast foods. Those reported having high blood pressure were $111(17.5 \%)$ and of those only $22(19.9 \%)$ measure it regularly. Diabetes was reported in $65(10.2 \%)$ of those only $31(47.7 \%)$ monitor their blood sugars regularly. Table 2 reveals to us the conditions diagnosed with the participants. Hypertension is the highest disease diagnosed with a total of $111(17.5 \%)$ and highest among females with $71(64.0 \%)$. The second most upper disease diagnosed is obesity, with $110(17.3 \%)$ and highest among females as well, with $71(64.5 \%)$. High cholesterol is the third highest with $80(12.6 \%)$ and highest among females with $52(65.0 \%)$ followed by those diagnosed with diabetes mellitus with 65 (10.2\%), which is also highest among females with 34 (52.3\%). Prior heart attack or heart disease are reported by 16 participants (12.5\%). Females have the highest percentage of diagnosed conditions except in prior stroke as it is identical in both sexes.

\section{Knowledge of Cardiovascular Disease}

Table 3 shows the respondent's knowledge about the symptoms of a heart attack. The majority of the participants identified chest pain and discomfort (76.4\%) and shortness of breath (73.7\%) as symptoms of a heart attack compared with other symptoms such as pain or discomfort in arm or shoulder (57.3\%), weakness in the arm or leg on one side of the body $(55.6 \%)$, and weakness lightheaded and fainting $(51.2 \%)$. A reasonably high response rate of participants who did not know whether some symptoms were for heart attack. When asked which symptoms were of heart attack shortness of breath 468(73.7) was reported the highest and trouble seeing in one or both eyes was reported the least. None reached statistical significance $(\mathrm{p}<0.05)$ except "weakness in the arm or leg in one side of the body" with a p-value of (0.005), "pain or discomfort in arm or shoulder" with p-value (0.001), and "shortness of breath" with a p-value of (0.001). Table 4 shows the participants' knowledge of heart attack risk factors. The majority 496(78.1\%) of the participants identified smoking as the highest risk factor, excess salt intake being the lowest at 318(50.1\%). None of the risk factors reached statistical significance ( $p>0.05)$.

Table 1: Demographic and Clinical Characteristics of study participants ( $n=635)$

\begin{tabular}{|l|l|}
\hline Characteristics & Frequency (\%) \\
\hline Gender & \\
\hline Male & $228(35.9)$ \\
\hline Female & $407(64.1)$ \\
\hline Marital Status & $345(54.3)$ \\
\hline Single & $290(45.7)$ \\
\hline Married & \\
\hline Age & $347(54.6)$ \\
\hline $20-29$ & $116(18.3)$ \\
\hline $30-39$ & $91(14.3)$ \\
\hline $40-49$ & $65(10.2)$ \\
\hline $50-59$ & $16(2.5)$ \\
\hline$\geq 60$ :SEF: & \\
\hline Employment & $380(59.8)$ \\
\hline Unemployed & $255(40.2)$ \\
\hline Employed & \\
\hline Educational Level & $131(20.6)$ \\
\hline Low-intermediate education & $504(79.4)$ \\
\hline High education & \\
\hline Lifestyle & $79(12.4)$ \\
\hline Very stressful & $161(25.4)$ \\
\hline Stressful & $278(43.8)$ \\
\hline Relatively stressful & \\
\hline
\end{tabular}


International Journal of Innovative Research in Medical Science (IJIRMS)

\begin{tabular}{|c|c|}
\hline Free from stress & $117(18.4)$ \\
\hline \multicolumn{2}{|l|}{ Smoker } \\
\hline Yes & $188(29.6)$ \\
\hline No & $447(70.4)$ \\
\hline \multicolumn{2}{|l|}{30 Minutes exercise /week } \\
\hline $1-2$ times & $173(27.2)$ \\
\hline $3-4$ times & $125(19.7)$ \\
\hline More than 5 times a week & $43(6.8)$ \\
\hline I don't exercise & $294(46.3)$ \\
\hline \multicolumn{2}{|c|}{ Do you eat vegetables and fruits daily? } \\
\hline Frequently & $185(29.1)$ \\
\hline Sometimes & $372(58.6)$ \\
\hline No & $78(12.3)$ \\
\hline \multicolumn{2}{|l|}{ Do you eat fast food? } \\
\hline Yes & $252(39.7)$ \\
\hline No & $52(8.2)$ \\
\hline Sometimes & $258(40.6)$ \\
\hline Rarely & $73(11.5)$ \\
\hline \multicolumn{2}{|l|}{ Family History of CVD } \\
\hline Yes & $217(34.2)$ \\
\hline No & $418(65.8)$ \\
\hline $\begin{array}{l}\text { Are you Hypertensive? } \\
\text { Yes } \\
\text { No } \\
\text { If yes, do you measure yo }\end{array}$ & $\begin{array}{l}111(17.5) \\
524(82.5)\end{array}$ \\
\hline Yes & $22(19.9)$ \\
\hline No & $89(80.1)$ \\
\hline $\begin{array}{l}\text { Are you Diabetic? } \\
\text { Yes } \\
\text { No } \\
\text { If yes, do you monitor yo }\end{array}$ & $\begin{array}{l}65(10.2) \\
570(89.8)\end{array}$ \\
\hline Yes & $31(47.7)$ \\
\hline No & $34(52.3)$ \\
\hline
\end{tabular}

Table 2: Conditions diagnosed to participants

\begin{tabular}{|c|c|c|c|c|c|}
\hline & \multicolumn{5}{|c|}{ Have you Been Diagnosed with the Following Conditions Before? } \\
\hline & & \multicolumn{2}{|c|}{ Gender } & \multirow[t]{2}{*}{ Frequency $(\%)$} & P-value \\
\hline & & Male & Female & & \multirow{3}{*}{0.975} \\
\hline \multirow[t]{2}{*}{ Hypertension } & Yes & 40 & 71 & 111 & \\
\hline & $\%$ & 36.0 & 64.0 & 17.5 & \\
\hline \multirow[t]{2}{*}{ Diabetes Mellitus } & Yes & 31 & 34 & 65 & \multirow[t]{2}{*}{0.037} \\
\hline & $\%$ & 47.7 & 52.3 & 10.2 & \\
\hline \multirow[t]{2}{*}{ High Cholesterol } & Yes & 28 & 52 & 80 & \multirow[t]{2}{*}{0.857} \\
\hline & $\%$ & 35.0 & 65.0 & 12.6 & \\
\hline \multirow[t]{2}{*}{ Obesity } & Yes & 39 & 71 & 110 & 0.914 \\
\hline & $\%$ & 35.5 & 64.5 & 17.3 & \\
\hline \multirow[t]{2}{*}{ Prior Heart Attack or Heart Disease } & Yes & 5 & 11 & 16 & \multirow[t]{2}{*}{0.897} \\
\hline & $\%$ & 31.2 & 68.8 & 2.5 & \\
\hline \multirow[t]{2}{*}{ Prior Stroke } & Yes & 1 & 1 & 2 & 0.677 \\
\hline & $\%$ & 50.0 & 50.0 & 0.3 & \\
\hline \multirow[t]{2}{*}{ Not Diagnosed } & Yes & 141 & 250 & 224 & \multirow[t]{2}{*}{0.917} \\
\hline & $\%$ & 36.1 & 63.9 & 38.4 & \\
\hline
\end{tabular}

*Not included: percentages of those not diagnosed for each category.

Table 3: Knowledge and Symptoms of Heart Attack

Which of the Following Do You Think are Symptoms of Heart Attack?

\begin{tabular}{|c|c|c|c|c|c|}
\hline & & \multicolumn{2}{|c|}{ Gender } & \multirow[t]{2}{*}{ Frequency $(\%)$} & \multirow[t]{2}{*}{ P-Value } \\
\hline & & Male & Female & & \\
\hline \multirow[t]{3}{*}{ Pain in Jaw Neck or Back } & Yes & 79 & 152 & $231(36.4)$ & \multirow[t]{3}{*}{0.626} \\
\hline & No & 75 & 120 & $195(30.7)$ & \\
\hline & I don't know & 74 & 135 & $209(32.9)$ & \\
\hline
\end{tabular}




\begin{tabular}{|c|c|c|c|c|c|}
\hline \multirow{3}{*}{$\begin{array}{l}\text { Weakness in the arm or leg on one side of the } \\
\text { body }\end{array}$} & Yes & 108 & 246 & $354(55.7)$ & \multirow[t]{3}{*}{0.005} \\
\hline & No & 62 & 76 & $138(21.7)$ & \\
\hline & I don't know & 58 & 85 & $143(22.5)$ & \\
\hline \multirow[t]{3}{*}{ Weakness, Lightheaded, fainting } & Yes & 117 & 208 & $325(51.2)$ & \multirow[t]{3}{*}{0.097} \\
\hline & No & 59 & 81 & $140(22.0)$ & \\
\hline & I don't know & 52 & 118 & $170(26.8)$ & \\
\hline \multirow[t]{3}{*}{ Chest pain, discomfort } & Yes & 160 & 327 & $487(76.7)$ & \multirow[t]{3}{*}{0.010} \\
\hline & No & 33 & 45 & $78(12.3)$ & \\
\hline & I don't know & 35 & 35 & $70(11)$ & \\
\hline \multirow[t]{3}{*}{ Trouble seeing in one or both eyes } & Yes & 91 & 138 & $229(36.1)$ & \multirow[t]{3}{*}{0.267} \\
\hline & No & 64 & 119 & $183(28.8)$ & \\
\hline & I don't know & 73 & 150 & $223(35.1)$ & \\
\hline \multirow[t]{3}{*}{ Pain or discomfort in arm or shoulder } & Yes & 107 & 257 & $364(57.3)$ & \multirow[t]{3}{*}{0.001} \\
\hline & No & 55 & 64 & $119(18.7)$ & \\
\hline & I don't know & 66 & 86 & $152(23.9)$ & \\
\hline \multirow[t]{3}{*}{ Shortness of Breath } & Yes & 145 & 324 & $469(73.9)$ & \multirow[t]{3}{*}{0.001} \\
\hline & No & 38 & 32 & $70(11.0)$ & \\
\hline & I don't know & 45 & 51 & $96(15.1)$ & \\
\hline
\end{tabular}

Table 4: Knowledge of Heart Attack Risk Factors

\begin{tabular}{|c|c|c|c|c|c|}
\hline \multicolumn{6}{|c|}{ Which of the Following Do You Think are Causes of Heart Attack? } \\
\hline & & $\underline{\text { Male }}$ & Female & & \\
\hline \multirow[t]{3}{*}{ Hypertension } & Yes & 161 & 301 & $462(72.8)$ & \multirow[t]{3}{*}{0.645} \\
\hline & No & 29 & 44 & $73(11.5)$ & \\
\hline & I don't know & 38 & 62 & $100(15.7)$ & \\
\hline \multirow[t]{3}{*}{ High Cholesterol } & Yes & 150 & 299 & $449(70.7)$ & \multirow[t]{3}{*}{0.061} \\
\hline & No & 37 & 42 & $79(12.4)$ & \\
\hline & I don't know & 41 & 66 & $107(16.9)$ & \\
\hline \multirow[t]{3}{*}{ Smoking } & Yes & 175 & 321 & $496(78.1)$ & \multirow[t]{3}{*}{0.798} \\
\hline & No & 21 & 36 & $57(9.0)$ & \\
\hline & I don't know & 32 & 50 & $82(12.9)$ & \\
\hline \multirow[t]{3}{*}{ Alcoholism } & Yes & 133 & 259 & $392(61.7)$ & \multirow[t]{3}{*}{0.212} \\
\hline & No & 41 & 53 & $94(14.8)$ & \\
\hline & I don't know & 54 & 95 & $149(23.5)$ & \\
\hline \multirow[t]{3}{*}{ Excess Salt Intake } & Yes & 121 & 197 & $318(50.1)$ & \multirow[t]{3}{*}{0.478} \\
\hline & No & 44 & 92 & $136(21.4)$ & \\
\hline & I don't know & 63 & 118 & $181(28.5)$ & \\
\hline
\end{tabular}

\section{Discussion}

This is the first known study to be conducted in Saudi Arabia, Jeddah, to comprehensively demonstrate the current level of public knowledge about CVD's warning symptoms and risk factors. This study's objectives were to characterize the symptoms and factors related to CVD knowledge in the Saudi population. A very worrisome finding in the current study was the respondents' low knowledge of CVD symptoms. The first sign is chest pain, which was the most common reported $(76.4 \%)$, which is close to that found in Nigeria (67\%) and Beijing (64\%) but higher than that reported in Kuwait (50\%), Pakistan (36\%), and Nepal. People's awareness of chest pain and their relationship to CVD was acceptable, but it requires more education about the symptoms associated with $\mathrm{CVD}^{[7,8,9,10,11]}$.

Saudi society awareness about Shortness of breath was recognized by $(73.7 \%)$ of the study population, which is consistent with that reported in Nigeria (62\%), but higher than that in Canada (39\%), Pakistan (24\%), Kuwait (48\%), and Nepal (13\%) ${ }^{[7,9,10,11,11]}$. Pain in arms or shoulder was identified by $(56 \%)$ of respondents, which is higher than that reported by studies from Nigeria (28\%) and Kuwait $(48 \%)^{[9,10,11,11]}$. followed by numbness or weakness of the face, arm, or leg (55\%). Feeling weak, light-headed, or faint was recognized by $(51.2 \%)$ of participants, close to that reported in Nigeria (41\%), and lower than in Kuwait (25\%) ${ }^{[7,9,10,11]}$. Knowledge about Symptoms of Heart Attack in CVD was significantly $\mathrm{p}<0.05$ different in weakness in the arm or leg on one side of the body, chest pain, discomfort, pain in arms or shoulder, and shortness of breath.

Respondents' knowledge about the causes of heart attack. In this study, the most common identified cause of heart attack was smoking $(78.1 \%)$, which is consistent with the report in Kuwait $(88.7 \%)$ and Jordan $(75.7 \%)$.It is higher than that in previous studies of Nigeria (48.8\%), Canada (55\%), Iran (67.5\%), Pakistan(31.9\%), and $\operatorname{Nepal}(5.8 \%){ }^{[7,9,10,11,12,13,14]}$. The second mostly known risk factor by the participants was hypertension (72\%), which can cause many diseases such as heart failure and lead to complications this is similar to Nigeria (73.2\%), but higher than Kuwait (64.3\%), Jordan (62\%), Iran (54\%), Canada (20\%), Pakistan (7.10\%), and Nepal (13.3\%) ${ }^{[7,9,10,11,12,13]}$. The Saudi population's high cholesterol awareness as a risk factor for heart attack was (70\%); it corresponds to Kuwait's report (69.7\%), but higher than in Nigeria (37.6\%), Canada (31\%), Nepal (15.6\%) and 
Pakistan $(7.40 \%)^{[7,9,10,11,12]}$. The knowledge of heart attack risk factors such as smoking, hypertension, high cholesterol is higher than that of alcoholism and excess salt intake, which is similar to the report of Nigeria and Canada. $(5,6)$ Low knowledge and understanding of CVD have been reported elsewhere in the literature. Potvin and colleagues (2000) said there is a lack of knowledge about certain CVD risk factors in Canada ${ }^{[3]}$.

Respondents' knowledge about the risk factors of heart attack of a heart attack in CVD was better than the symptoms of a heart attack. This increased understanding of CVD risk factors is related to their significant representation in mass media and promotions, as opposed to CVD's warning. Respondents' higher knowledge about these risk factors, may be related to the statistic, and the questions were taken through the mall. Its visitors are mostly intellectuals; their awareness and education are high because most of them are aware of some heart attack causes. Therefore, they know how dangerous these risk factors are related to CVD in addition to the intensive representation in mass media campaigns as opposed to a symptom of a heart attack, which were identified less frequently by the study population. Factors significantly associated with CVD are diabetes mellitus with $\mathrm{p}$ value 0.037 When comparing our results to those of Northern Ireland and Jorden studies, it must be pointed out that Northern Ireland was higher with $\mathrm{p}$ value 0.117 and Jordan was lower with $\mathrm{p}$ value $0.013^{[14,15]}$

Some limitations during this study; firstly, this is a cross sectional study and the data represented are in one point of time and therefore does not reflect any change in respondent's knowledge about CVS. Secondly, this is a self-administered questionnaire and cardiac examinations are needed. Thirdly, this study was only conducted in Jeddah therefore we can't generalize the results. These present findings highlighted the need for further improvement of the public knowledge regarding symptoms and causes of CVD among the Saudi population.

Lack of knowledge of symptoms of heart attacks can increase the delay in seeking early medical care, leading to worse therapeutic outcomes.

\section{Conclusion}

This study demonstrates the baseline levels of knowledge about CVD types, warning symptoms of heart attack or stroke, and CVD risk factors among the general population in Jeddah, Saudi Arabia. The study participants show low knowledge in CVS. There is a need to increase public awareness and to establish basic knowledge to the general and targeted individuals.

\section{Funding}

This research received no funding

\section{Conflict of Interest}

The authors declare no conflict of Interest

\section{Author's contributions}

Shereen Helmy Ahmed: conception and design of study, literature review, designed the methodology, data collection, drafting the manuscript, revising and editing the manuscript, supervised the research, coordinated and managed the research
Yumna Abdulmalek Bokhari: literature review, designed the methodology, analysis of data, data collection, drafting the manuscript

Rana Jamal Nahas: literature review, data collection, drafting the manuscript

Amjad zaki Alharbi: literature review, data collection, drafting the manuscript

Asrar Abdullah Niyazi: literature review, data collection, drafting the manuscript

Renad Abdulwahab AlGaedy: literature review, data collection, drafting the manuscript

\section{Acknowledgment}

The authors would like to express their sincere gratitude to the data collectors: Asaiel Zaki Alrehaili, Amani Zaki Alrehaili, Lana Abdulwahab AlGaedy, Rafal Abdulwahab AlGaedy, Rana yousef almaghrabi

\section{References}

[1] Global Status Report on NCDs [Internet]. World Health Organization. 2021 [cited 13 February 2021]. Available from:

https://www.who.int/chp/ncd_global_status_report/en/

[2] [Internet]. 2021 [cited 13 February 2021]. Available from:

https://www.moh.gov.sa/en/Ministry/MediaCenter/News /Pages/News-2013-10-30-002.aspx

[3] Alharthi FS, Alrahimi JS, Alotaibi AA, Alhamdi DA, Ibrahim BM, Badeeb YA. Prevalence of undiagnosed cardiovascular risk factors in adults aged 20-40: a crosssectional Study in 2016 in Jeddah, Saudi Arabia. Cardiology research. 2017 Jun;8(3):111.

[4] Ghamri RA, Alzahrani NS, Alharthi AM, Gadah HJ, Badoghaish BG, Alzahrani AA. Cardiovascular risk factors among high-risk individuals attending the general practice at king Abdulaziz University hospital: a crosssectional study. BMC cardiovascular disorders. $2019 \mathrm{Dec}$ 1;19(1):268.

[5] Rezk-Hanna M, Benowitz NL. Cardiovascular Effects of Hookah Smoking: Potential Implications for Cardiovascular Risk [Internet]. OUP Academic. Oxford University Press; 2018 [cited 2021May2]. Available from: https://academic.oup.com/ntr/articleabstract/21/9/1151/4961557

[6] Sample Size Calculator by Raosoft, Inc. [Internet]. [cited 2020 Jul 2]. Available from: http://www.raosoft.com/samplesize.html?nosurvey

[7] Kolo PM, Ogunmodede JA, Sanya EO, Bello HS, Ghadamosi MS, Dele-Ojo BF, Katibi IA, Omotoso AB. Public knowledge of heart attack symptoms and prevalence of self-reported cardiovascular risk factors in Ilorin, Nigeria. Nigerian Journal of Cardiology. 2015 Jul 1;12(2):95.

[8] Zhang QT, Hu DY, Yang JG, Zhang SY, Zhang XQ, Liu SS: Public knowledge of heart attack symptoms in Beijing residents. Chin Med J (Engl) 2007, 120:15871591.

[9] Awad A, Al-Nafisi H. Public knowledge of cardiovascular disease and its risk factors in Kuwait: a cross-sectional survey. BMC Public Health. 2014;14:1131. 
[10] Jafary FH, Aslam F, Mahmud H, Waheed A, Shakir M, Afzal A, Qayyum MA, isiepiam J, Khan IS, Haque IU: Cardiovascular health knowledge and behavior in patient attendants at four tertiary care hospitals in Pakistan- a

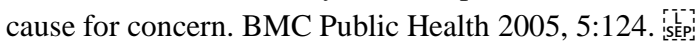

[11] Vaidya ARAU, Krettek A: Cardiovascular health knowledge, attitude and practice/behaviour in an urbanising community of Nepal: a population- based cross-sectional study from Jhaukhel-Duwakot Health Demographic Surveillance Site. BMJ Open 2013, 3:e002976.

[12] Gill R, Chow CM: Knowledge of heart disease and stroke among cardiology inpatients and outpatients in a Canadian inner-city urban hospital. Can J Cardiol 2010, 26:537-540. is isep:
[13] Mazloomy SS, Baghianimoghadam MH, Ehrampoush MH, Baghianimoghadam B, Mazidi M, Mozayan MR: A study of the knowledge, attitudes, and practices (KAP) of the women referred to health centers for cardiovascular disease (CVDs) and their risk factors. Health Care Women Int 2014, 35:50-59.

[14] Mukattash TL, Shara M, Jarab AS, Al-Azzam SI, Almaaytah A, Al Hamarneh YN: Public knowledge and awareness of cardiovascular disease and its risk factors: a cross-sectional study of 1000 Jordanians. Int J Pharm Pract 2012, 20:367-376.

[15] Al Hamarneh, Y. N., Crealey, G. E., \& McElnay, J. C. . Coronary heart disease: health knowledge and behaviour. International journal of clinical pharmacy, 2011 